\title{
Fibrous dysplasia of bone: Surgical management options and outcomes of 22 cases
}

\author{
XIANG FANG $^{1 *}$, HONGYUAN LIU ${ }^{1 *}$, YUN LANG $^{1,2}$, YAN XIONG $^{1}$ and HONG DUAN ${ }^{1}$ \\ ${ }^{1}$ Department of Orthopedics, West China School of Medicine, West China Hospital, Sichuan University, Chengdu, \\ Sichuan 610064; ${ }^{2}$ Department of Orthopedics, People's Hospital of Deyang City, Deyang, Sichuan 618000, P.R. China
}

Received February 2, 2018; Accepted May 15, 2018

DOI: $10.3892 /$ mco.2018.1636

\begin{abstract}
The surgical treatment for fibrous dysplasia (FD) of bone is problematic due to its variable clinical courses. And multifarious surgical treatment options have been reported while no consistent view can be reached. Therefore, we reviewed a series of 22 patients ( 11 males and 11 females; mean age 28.4 years, range 15-48 years) with FD between December 2011 and July 2015. Fourteen patients had monostotic fibrous dysplasia (MFD) and eight patients had polyostotic fibrous dysplasia (PFD) with nine lesions. All patients were followed up from 15 to 58 months with an average of 26.0 months. Functional and radiographic outcomes were recorded. In the MFD group, four patients were treated with curettage and bone grafting without internal fixation and nine were treated with curettage and bone grafting with internal fixations. Osteotomy and intramedullary (IM) nail was applied in one patient with serious deformity. In the PFD group, three deformity lesions were treated with osteotomy and proximal femoral nail anti-rotation (PFNA). IM were also applied in six large lesions to treat fracture or prevent deformity. One lesion in tibia were treated with only curettage and bone graft. No complication was observed in MFD group and satisfactory union and functional outcomes acquired during follow-up period. In the PFD group, the spiral blade cutting out from femoral head in PFNA was observed in one patient and treated with revision surgery. No other complication occurred, and satisfactory radiological and functional outcome were observed. The severity of both MFD and PFD are related to size, site and of the lesion. The goal of the surgery is to eliminate pain, correct deformity and treat pathological fracture. Curettage, bone grafting with internal fixation is recommended for treating
\end{abstract}

Correspondence to: Dr Hong Duan, Department of Orthopedics, West China School of Medicine, West China Hospital, Sichuan University, 37 Guo Xue Lane, Chengdu, Sichuan 610064, P.R. China E-mail: duanhong1970@126.com

*Contributed equally

Key words: fibrous dysplasia, curettage, bone grafting, internal fixation, osteotomy large lesions with deformity or high pathological fracture risk. PFNA or IM nail is prior in osteotomy with better clinical outcome.

\section{Introduction}

Fibrous dysplasia (FD) is a benign developmental anomaly of intramedullary fibro-osseous tumorlike lesion characterized by substituting fibrous connective tissue for normal bone and marrow (1-3). It accounts for approximately 5\% of benign bone tumors around the world (4) and the incidence in China is $10-30$ cases per million (5). The craniofacial, axial, and/or appendicular skeleton can be involved separately or simultaneously by fibrous dysplasia, ranging from isolated asymptomatic monostotic lesions uncovered accidentally to grave incapacitating polyostotic lesions leading to pain, fracture, deformity or loss of vision and hearing (6-8).

The surgical treatment of fibrous dysplasia of bone is a challenge to orthopedic surgeons due to its wide clinical spectrum and variation such as massive involvement, deformity and pathological fracture.

There are no clear guidelines established for orthopedic management of fibrous dysplasia of bone. Multifarious treatments are reported based on the initial assessment age, location and type of the lesion including conventional surgical procedures like curettage or en bloc resection with bone grafting in monostotic lesions and specific interventions like osteotomy with internal fixation aiming at the prevention or correction of bony deformities in extended lesions (5,9-15). Therefore, we undertook a retrospective study of 22 patients and share our findings about FD in terms of surgical management and outcomes.

\section{Materials and methods}

A retrospective study was performed in 22 patients (23 lesions) histologically diagnosed with fibrous dysplasia (FD) who were surgically treated in our hospital between December 2011 and July 2015 (Including one patient with two lesions, whose tibia lesion was treated in another institute). Of these 22 patients, the sex ratio was $1: 1$ and the age at operation ranged from 15 to 48 years with an average of 28.4 years.

Surgical operations including curettage and bone grafting with or without internal fixation and osteotomy were planned 
Table I. Clinical data.

\begin{tabular}{|c|c|c|c|c|c|c|c|c|}
\hline Case & Sex & $\begin{array}{c}\text { Age at } \\
\text { operation }\end{array}$ & $\begin{array}{l}\text { Lesion } \\
\text { type }\end{array}$ & $\begin{array}{l}\text { Follow-up } \\
\text { period } \\
\text { (months) }\end{array}$ & $\begin{array}{l}\text { Primary } \\
\text { complaints }\end{array}$ & $\begin{array}{l}\text { Lesions } \\
\text { undergone } \\
\text { surgery }\end{array}$ & Site & Treatment \\
\hline 1 & Male & 16 & M & 37.1 & Pain & Ilium & $\mathrm{L}$ & CUR+BCG \\
\hline 2 & Female & 45 & M & 23.7 & Pain & Ilium & $\mathrm{L}$ & CUR+BCG \\
\hline 3 & Male & 31 & M & 17.1 & Found by chance & Ilium & $\mathrm{R}$ & CUR+BCG \\
\hline 4 & Male & 45 & M & 18.3 & Found by chance & Ilium & $\mathrm{L}$ & CUR+BCG \\
\hline 5 & Male & 42 & M & 21.3 & Pain & Proximal femur & $\mathrm{R}$ & CUR+BCG+PFNA \\
\hline 6 & Male & 50 & M & 16.5 & Pain & Proximal femur & $\mathrm{R}$ & CUR+BCG+DHS \\
\hline 7 & Male & 25 & M & 16.4 & Found by chance & Proximal femur & $\mathrm{L}$ & CUR+BCG+DHS \\
\hline 8 & Female & 21 & M & 17.0 & Pain & Proximal femur & $\mathrm{L}$ & $\mathrm{CUR}+\mathrm{BCG}+\mathrm{DHS}$ \\
\hline 9 & Male & 38 & M & 16.8 & Found by chance & Proximal femur & $\mathrm{L}$ & CUR+BCG+DHS \\
\hline 10 & Female & 42 & M & 17.0 & Pain & Proximal femur & $\mathrm{R}$ & CUR+BCG+DHS \\
\hline 11 & Female & 19 & M & 22.0 & Pain & Proximal femur & $\mathrm{L}$ & CUR+BCG+DHS \\
\hline 12 & Male & 18 & M & 21.5 & Pain & Proximal femur & $\mathrm{L}$ & $\mathrm{OST}+\mathrm{CUR}+\mathrm{BCG}+\mathrm{IMN}$ \\
\hline 13 & Male & 16 & M & 17.6 & Fracture & Middle humerus & $\mathrm{L}$ & CUR+BCG+P\&S \\
\hline 14 & Female & 27 & M & 18.5 & Fracture & Middle humerus & $\mathrm{R}$ & CUR+FG+P\&S \\
\hline 15 & Male & 20 & $\mathrm{P}$ & 23.4 & Pain and limp & Tibia & $\mathrm{L}$ & $\mathrm{OST}+\mathrm{CUR}+\mathrm{BCG}+\mathrm{IMN}$ \\
\hline 16 & Female & 48 & $\mathrm{P}$ & 20.1 & Pain and limp & Proximal femur & $\mathrm{R}$ & $\mathrm{OST}+\mathrm{CUR}+\mathrm{BCG}+\mathrm{IMN}$ \\
\hline 17 & Female & 16 & $\mathrm{P}$ & 36.9 & Pain and limp & Proximal femur & $\mathrm{R}$ & $\mathrm{OST}+\mathrm{CUR}+\mathrm{BCG}+\mathrm{PFNA}$ \\
\hline 18 & Female & 15 & $\mathrm{P}$ & 27.1 & Pain & Tibia & $\mathrm{L}$ & IMN \\
\hline $19 a^{a}$ & Male & 17 & $\mathrm{P}$ & 43.1 & Pain & Tibia & $\mathrm{R}$ & CUR+BCG+IMN \\
\hline $19 b$ & Male & 18 & $\mathrm{P}$ & 30.6 & Pain & Proximal femur & $\mathrm{R}$ & CUR+BCG+PFNA \\
\hline 20 & Female & 40 & $\mathrm{P}$ & 51.8 & Pain & Total femur & $\mathrm{L}$ & CUR+BCG+IMN \\
\hline 21 & Female & 16 & $\mathrm{P}$ & 15.9 & Fracture & Total femur & $\mathrm{L}$ & CUR+BCG+PFNA \\
\hline $22 \mathrm{a}$ & Female & 17 & $\mathrm{P}$ & 58.6 & Pain & Proximal femur & $\mathrm{L}$ & CUR+BCG+PFNA \\
\hline $22 b$ & Female & 21 & $\mathrm{P}$ & 15.1 & Pain & Tibia & $\mathrm{L}$ & CUR+BCG+AG \\
\hline
\end{tabular}

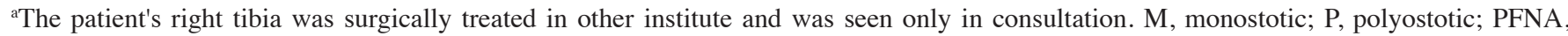
proximal femoral nail anti-rotation; DHS, dynamic hip screw; IMN, intramedullary nail; P\&S, plate and screws; OST, osteotomy; CUR, curettage; BCG, bone chips grafting; FG, fibula grafting; AG, allografting.

upon symptoms, impending fracture or progressive deformity. Internal fixations were all provide by DePuy-Synthes, Paoli, CA, USA and included plate and screws (P\&S), dynamic hip screw (DHS), intramedullary nail (IMN), proximal femoral nail anti-rotation (PFNA). And massive allografts and internal fixations were applied in lesions with low bone stock left after curettage. Limited weight-bearing were allowed for all postoperative patients for about 3 months.

To analysize the outcome, the functional evaluation system of the Musculoskeletal Tumor Society (MSTS) score was used in numberical scores and percentage rates caculated for the extremities invovled. A percentage rate of over $70 \%$ was considered to be a satisfactory result (16). The radiographic result was considered as satisfactory, if there was no local recurrence, pathological fracture, progression of deformity or nonunion of bone.

This study was conducted in accordance with the Declaration of Helsinki and with approval from the Ethics Committee of West China Hospital (Chengdu, China). Written informed consent was obtained from all participants or their guardians.

\section{Results}

Fourteen patients had a monostotic disease (MFD), of which four patients were asymptomatic, eight patients presented with pain and the other two had pathological fracture. Seven patients had polyostotic disease (PFD) with complication of pain and two of which suffered from pathological fracture. Further details on sex, primary complaint, medical course, location, and treatment were listed on Table I. And the detailed clinical outcome was shown in Table II.

Monostotic group. Four patients (4/14) in the monostotic group were asymptomatic, including two ilia and two proximal femurs. They were treated with curettage and bone grafting with or without internal fixations. Osteotomy, curettage, bone grafting and internal fixation were applied in one patient with pain and shepherd crook deformity in proximal femur. Two patients presented with pathological fracture of the middle humerus and were treated with curettage, bone grafting, internal fixation of plate and screws (One typical case was showed in Fig. 1). Two patients with a symptomatic lesion in 
Table II. Details of treatment outcome.

\begin{tabular}{|c|c|c|c|c|c|c|}
\hline \multirow[b]{2}{*}{ Case } & \multirow[b]{2}{*}{ Lesions } & \multirow[b]{2}{*}{ Treatment } & \multicolumn{2}{|c|}{ MSTS } & \multirow{2}{*}{$\begin{array}{l}\text { Radiographic } \\
\text { results }\end{array}$} & \multirow{2}{*}{$\begin{array}{c}\text { Complications and } \\
\text { management }\end{array}$} \\
\hline & & & Pre & Post & & \\
\hline $1^{\mathrm{a}}$ & Ilium & CUR+BCG & 24 & 29 & $\mathrm{~S}$ & None \\
\hline $2^{\mathrm{a}}$ & Ilium & $\mathrm{CUR}+\mathrm{BCG}$ & 24 & 30 & $\mathrm{~S}$ & None \\
\hline $3^{\mathrm{a}}$ & Ilium & $\mathrm{CUR}+\mathrm{BCG}$ & 27 & 29 & $\mathrm{~S}$ & None \\
\hline $4^{\mathrm{a}}$ & Ilium & $\mathrm{CUR}+\mathrm{BCG}$ & 27 & 30 & $\mathrm{~S}$ & None \\
\hline 5 & Proximal femur & CUR+BCG+PFNA & 17 & 28 & $\mathrm{~S}$ & None \\
\hline 6 & Proximal femur & CUR+BCG+DHS & 19 & 28 & $\mathrm{~S}$ & None \\
\hline 7 & Proximal femur & $\mathrm{CUR}+\mathrm{BCG}+\mathrm{DHS}$ & 28 & 29 & $\mathrm{~S}$ & None \\
\hline 8 & Proximal femur & $\mathrm{CUR}+\mathrm{BCG}+\mathrm{DHS}$ & 19 & 28 & $\mathrm{~S}$ & None \\
\hline 9 & Proximal femur & CUR+BCG+DHS & 27 & 29 & $\mathrm{~S}$ & None \\
\hline 10 & Proximal femur & CUR+BCG+DHS & 22 & 28 & $\mathrm{~S}$ & None \\
\hline 11 & Proximal femur & CUR+BCG+DHS & 22 & 29 & $\mathrm{~S}$ & None \\
\hline 12 & Proximal femur & $\mathrm{OST}+\mathrm{CUR}+\mathrm{BCG}+\mathrm{IMN}$ & 15 & 27 & $\mathrm{~S}$ & None \\
\hline 13 & Middle humerus & CUR+BCG+P\&S & 11 & 27 & $\mathrm{~S}$ & None \\
\hline 14 & Middle humerus & $\mathrm{CUR}+\mathrm{FG}+\mathrm{P} \& \mathrm{~S}$ & 10 & 28 & $\mathrm{~S}$ & None \\
\hline 15 & Tibia & $\mathrm{OST}+\mathrm{CUR}+\mathrm{BCG}+\mathrm{IMN}$ & 13 & 24 & $\mathrm{~S}$ & None \\
\hline 16 & Distal fibula & $\mathrm{OST}+\mathrm{CUR}+\mathrm{BCG}+\mathrm{IMN}$ & 24 & 26 & $\mathrm{~S}$ & None \\
\hline 17 & Proximal femur & $\mathrm{OST}+\mathrm{CUR}+\mathrm{BCG}+\mathrm{PFNA}$ & 13 & 25 & $\mathrm{~S}$ & None \\
\hline 18 & Tibia & IMN & 20 & 28 & $\mathrm{~S}$ & None \\
\hline $19 a^{b}$ & Tibia & CUR+BCG+IMN & - & 28 & $\mathrm{~S}$ & None \\
\hline $19 \mathrm{~b}$ & Proximal femur & CUR+BCG+PFNA & 19 & 28 & $\mathrm{~S}$ & None \\
\hline 20 & Total femur & CUR+BCG+IMN & 17 & 25 & $\mathrm{~S}$ & None \\
\hline 21 & Total femur & CUR+BCG+PFNA & 4 & 11 & $\mathrm{U}$ & $\begin{array}{c}\text { Spiral blade } \\
\text { cutting out; } \\
\text { Revision with AG; } \\
\text { Poor outcome }\end{array}$ \\
\hline $22 \mathrm{a}$ & Proximal femur & CUR+BCG+PFNA & 21 & 28 & $\mathrm{~S}$ & None \\
\hline $22 b$ & Tibia & $\mathrm{CUR}+\mathrm{BCG}+\mathrm{AG}$ & 23 & 27 & $\mathrm{~S}$ & None \\
\hline
\end{tabular}

${ }^{a}$ The MSTS for these patients with ilium lesions was rated according to the standard for lower limbs; ${ }^{\mathrm{b}}$ The patient's right tibia was surgically treated in other institute and was seen only in consultation. Pre, Preoperatively; Post, Postoperatively; MSTS, the Musculoskeletal Tumor Society score; U, unsatisfactory; S, satisfactory; PFNA, proximal femoral nail anti-rotation; DHS, dynamic hip screw; IMN, intramedullary nail; P\&S, plate and screws; OST, osteotomy; CUR, curettage; BCG, bone chips grafting; FG, fibula grafting; AG, allografting.

the none-weight-bearing ilium were treated with simple curettage and bone grafting, while the other five patients with a symptomatic lesion in the weight-bearing femur undergone curettage, bone grafting with dynamic hip screw (DHS) or proximal femoral nail anti-rotation (PFNA). Bone union and satisfactory radiographic and functional results were seen in all patients (mean age, 31.1 years) in the monostotic group in the last follow-up (mean, 20.1 months).

Polyostotic group. There were eight patients with a total of ten lesions undergone surgery in the polyostotic group. Three patients of two femurs and one tibia lesion had pain and severe deformities, one of them had pathological fracture.

Curettage and bone grafting with allograft of fibula or PFNA/IM nail was applied in six lesions with pain or pathological fracture. Case 22 had two significant lesions of proximal femur and tibia. Curettage, bone grafting and PFNA were performed on the femur lesion to relieve symptoms and prevent pathological fracture and deformity. As for tibia lesion, surgery of curettage and allograft without internal fixations was performed at four years after the first surgery due to progression and aggravating pain. Satisfactory outcome acquired during the last follow-up. In case 20, complication of spiral blade cutting out of the femoral head occurred at 6-month after the surgery of curettage, bone grafting and PFNA. And revision surgery of an allograft fibula implanted to replace the spiral blade was performed. But the radiographic and functional results were unsatisfactory at 16-month follow-up.

Three patients with deformity of lower limbs were treated with osteotomy, curettage, bone grafting and PFNA/intramedullary nail (One typical case was showed in Fig. 2). The patient No. 17 with extreme thin cortices of tibia were managed with intramedullary nail alone to prevent pathological fracture and progression. 

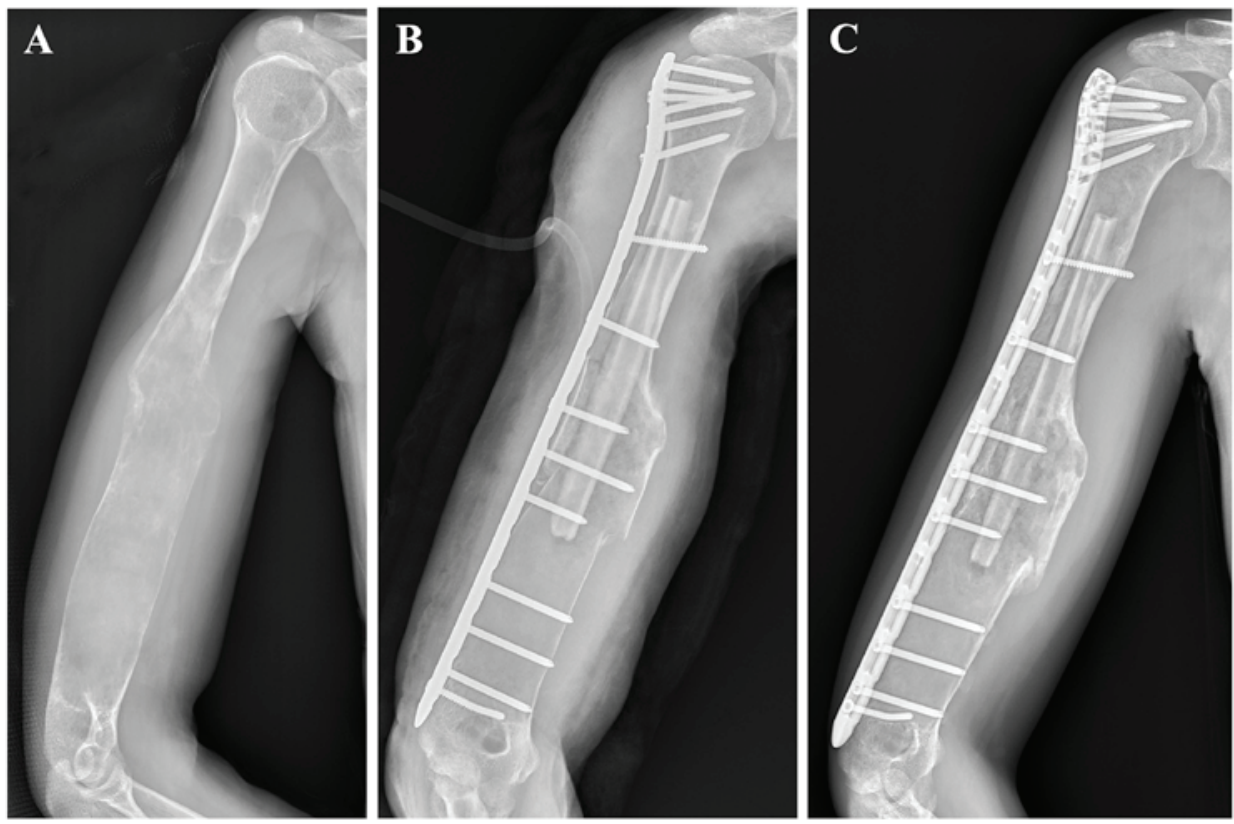

Figure 1. Case 14, a 27-year old female with MFD, who had pathological fracture of her right humerus. (A) Preoperative plain film showing pathological fracture of the middle humerus. (B) Curettage, fibula grafting and plate and screws were performed. (C) Postoperative 3 months' film showing fracture healed with no recurrence. And she had a satisfactory functional outcome with no disease progression in the last follow-up.
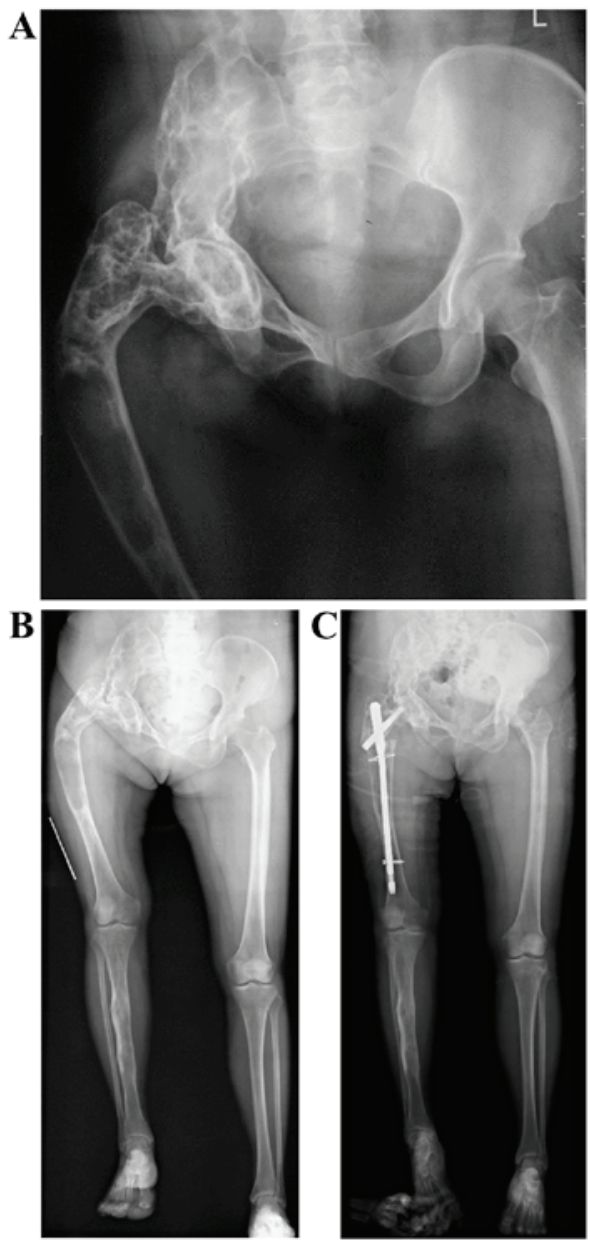

Figure 2. Case 8, a 48-year old female with PFD. (A) Preoperative pelvic plain film showed unilateral Shepherd's crook deformity. (B) Preoperative full-length plain film of bilateral lower limbs. (C) Postoperative film, osteotomy, bone-grafting and PFNA was performed. Bone union and good alignment with slightly absorb of bone-grafts was noted in the last follow-up and there was no evidence of recurrence.
All patients in the polyostotic group were followed up for averagely $34.6(15.9-58.6)$ months. The average age at the time of surgery was 23.6 (15-48) years. Except for Case 20, all (7/8) patients had satisfactory functional and radiologic results. There were no infection, recurrent fracture or progression of deformity.

\section{Discussion}

Fibrous dysplasia is an abnormal development of bone with multiple involvement and manifestations. There are no clear guidelines established for surgical treatment of the dysplastic lesions. In the present study, by retrospectively analyzing 22 patients with fibrous dysplasia and reviewing of the literatures $(11,17,18)$, we deduce that patient age, biological activity, location and size of the lesion are vital factors in surgical management options making and surgical outcomes expected.

Patient age is significant since monostotic lesions usually lose the potentiality to develop and become quiescent or biological inactive after skeletal maturity. While, polyostic lesions may continue to progress even in adulthood $(4,12,19)$, which indicates MFD may have a better prognosis than PFD. In our study, the mean age in the MFD group at operation was 30.1 (16-45) years as compared to 20.1 (15-40) years in the PFD group. All patients with MFD showed satisfactory outcome after surgery while one in seven patient from PFD group suffered hardware failure and unsatisfactory outcome, which is similar to the study by Döhler et al (20). He reported at least three in four (the rest was lost during followup) monostotic patients (mean age 40 years, range 22-61 years) had a satisfactory outcome while two in seven polyostic patients (three in ten lesions, mean age 6.9 years, range $2-14$ years) had a poor results postoperatively.

Harris et al (9) reported five in ten patients (ages: Unspecified) with a femoral neck lesion had a poor result after simple curettage and bone grafting (one with internal fixa- 
tion). But in our study four patients (ages: 16, 31, 45, 45 years) who had ilium involvement and underwent simple curettage and autograft had a satisfactory outcome and there were no recurrence noted upon the last followup. Stephenson et al (11) reported nine in ten skeletally mature patients (ages, $\geq 18$ years) with upper extremity lesion had a satisfactory outcome after curettage and bone grafting. We deduce that younger patient age and femoral lesion (of high mechanical forces) suggests relatively poorer prognosis treated with simple curettage and bone grafting, which concurs with the study by DiCaprio et al (7) that symptoms in active lesions are unlikely to be relieved with simple curettage and nonstructural bone grafting. For skeletally mature adults with MFD, curettage and bone grafting may be indicated (12). According to a recent multivariate analysis, polyostotic form may be the only risk factor of poor outcome (1). For young patients with PFD, bone grafts usually fail to incorporate and then are replaced by dysplastic lesions eventually, which suggests the significance of restoring the mechanical axes and reinforcing the bone with feasible internal fixations (21).

Underlying bone fragility in FD is common. Non-weight-bearing management for fractures will exacerbate the preexisting weakness of bone. Internal fixation allowing early weight-bearing should be considered when fracture occurs, especially in lower extremities. For lesions in the proximal femur, especially subtrochanteric fractures, intramedullary nailing is a reliable fixation choice $(13,22,23)$. By purchasing firmly into the femoral head, intramedullary nailing could stabilize the femur and prevent refractures and loss of neck shaft angle $(24,25)$. Typical plate and screw devices are not recommended (26). However, in our study satisfactory outcome were noted in all nine patients treated with DHS or plate and screws (six femurs and two humeri in MFD group, one distal fibula in PFD group). We presume that plate and screws should be used cautiously in selected lesions with sufficient normal cortical bone or on low-weight-bearing sites like fibula.

The bones especially the outer cortex are very thin, weak and easily deformed in PFD. It would become much thornier to manage, once fracture occurs upon deformity. In our study, Patient No.20 treated with curettage, graft and PFNA had complication and unsatisfactory outcome postoperatively which may related to minimal residual bone stock of femoral head and neck. The early prevention of bony deformities with corrective osteotomies and internal fixation is underlined in the literatures $(10,11,19)$ and allograft, known as having the least and slowest replacement by the host bones (7), may be the key to prevent recurrence and disease progression.

Limitation of the current study: We would have preferred to have a longer follow-up and more cases.

In conclusion, the management for monostotic patients mostly depends on symptoms. Surgical management for MFD is indicated in case of nonclassic presentation, potential mechanical deficit leading to pain or fracture. MFD usually ends with satisfactory outcome even with simple curettage and bone grafting in selected patients. For patients with PFD, apart from the measures above, osteotomy with PFNA or IM can correct bony deformity, prevent recurrent fracture, and restore alignment, thus improve functioning of limbs.

\section{Acknowledgements}

We thank Dr Yong Zhou and Dr Yi Luo (Department of Orthopedics, West China Hospital, Sichuan University, Chengdu, China) for the language assistance regarding this study

\section{Funding}

No funding was received.

\section{Availability of data and material}

The datasets used and analyzed during the current study are available from the corresponding author on reasonable request.

\section{Authors' contributions}

$\mathrm{XF}$ and $\mathrm{HL}$ analyzed and interpreted the patient data regarding the fibrous dysplasia disease and wrote the article. YL collected and analyzed the clinical data. HD and YX performed the surgeries and designed the structures of the manuscript. All authors read and approved the final manuscript.

\section{Ethics approval and consent to participate}

This study was conducted in accordance with the Declaration of Helsinki and with approval from the Ethics Committee of West China Hospital (Chengdu, China). Written informed consent was obtained from all participants or their guardians.

\section{Consent for publication}

Written informed consent was obtained from all participants or their guardians.

\section{Competing interests}

The authors declare that they have no competing interests.

\section{References}

1. Benhamou J, Gensburger D, Messiaen C and Chapurlat R: Prognostic factors from an epidemiologic evaluation of fibrous dysplasia of bone in a modern cohort: The FRANCEDYS study. J Bone Miner Res 31: 2167-2172, 2016.

2. Riminucci M, Robey PG, Saggio I and Bianco P: Skeletal progenitors and the GNAS gene: Fibrous dysplasia of bone read through stem cells. J Mol Endocrinol 45: 355-364, 2010.

3. Bianco P, Kuznetsov SA, Riminucci M, Fisher LW, Spiegel AM and Robey PG: Reproduction of human fibrous dysplasia of bone in immunocompromised mice by transplanted mosaics of normal and Gsalpha-mutated skeletal progenitor cells. J Clin Invest 101: 1737-1744, 1998.

4. Campanacci M: Bone and soft tissue tumors: Clinical features, imaging, pathology and treatment. Springer, New York, 1999.

5. Zhang X, Shang X, Wang Y, He R and Shi G: Intramedullary nailing for fibrous dysplasia of lower limbs. Oncol Lett 4: 524-528, 2012.

6. Amit M, Collins MT, FitzGibbon EJ, Butman JA, Fliss DM and Gil Z: Surgery versus watchful waiting in patients with craniofacial fibrous dysplasia-a meta-analysis. PLoS One 6: e25179, 2011.

7. DiCaprio MR and Enneking WF: Fibrous dysplasia. Pathophysiology, evaluation, and treatment. J Bone Joint Surg Am 87: 1848-1864, 2005. 
8. Satoh K, Mitsukawa N and Abe T: Is prophylactic decompression of the optic canal necessary in surgical correction of fronto-orbital fibrous dysplasia?: A review of 11 consecutive case. J Craniomaxillofac Surg 42: 1614-1616, 2014.

9. Harris WH, Dudley HR Jr and Barry RJ: The natural history of fibrous dysplasia. An orthopaedic, pathological, and roentgenographic study. J Bone Joint Surg Am 44-A: 207-233, 1962.

10. Guille JT, Kumar SJ and MacEwen GD: Fibrous dysplasia of the proximal part of the femur. Long-term results of curettage and bone-grafting and mechanical realignment. J Bone Joint Surg Am 80: 648-658, 1998.

11. Stephenson RB, London MD, Hankin FM and Kaufer H: Fibrous dysplasia. An analysis of options for treatment. J Bone Joint Surg Am 69: 400-409, 1987.

12. Enneking WF and Gearen PF: Fibrous dysplasia of the femoral neck. Treatment by cortical bone-grafting. J Bone Joint Surg Am 68: 1415-1422, 1986.

13. Freeman BH, Bray EW III and Meyer LC: Multiple osteotomies with Zickel nail fixation for polyostotic fibrous dysplasia involving the proximal part of the femur. J Bone Joint Surg Am 69: 691-698, 1987.

14. Hagiwara $\mathrm{Y}$, Iwata S, Yonemoto $\mathrm{T}$ and Ishii $\mathrm{T}$ : Rotational valgus osteotomy for shepherd's crook deformity: A case report. J Orthop Sci 20: 422-424, 2015.

15. Li L, Hou X, Li Q and Zhang L: En bloc resection and bone graft: Does it alter the natural history of monostotic expansile fibrous dysplasia in children? World J Surg Oncol 12: 349, 2014.

16. Enneking WF, Dunham W, Gebhardt MC, Malawar M and Pritchard DJ: A system for the functional evaluation of reconstructive procedures after surgical treatment of tumors of the musculoskeletal system. Clin Orthop Relat Res 286: 241-246, 1993.

17. Fitzpatrick KA, Taljanovic MS, Speer DP, Graham AR, Jacobson JA, Barnes GR and Hunter TB: Imaging findings of fibrous dysplasia with histopathologic and intraoperative correlation. AJR Am J Roentgenol 182: 1389-1398, 2004.
18. Zhibin Y, Quanyong L, Libo C, Jun Z, Hankui L, Jifang Z and Ruisen $\mathrm{Z}$ : The role of radionuclide bone scintigraphy in fibrous dysplasia of bone. Clin Nucl Med 29: 177-180, 2004.

19. Andrisano A, Soncini G, Calderoni PP and Stilli S: Critical review of infantile fibrous dysplasia: Surgical treatment. J Pediatr Orthop 11: 478-481, 1991

20. Döhler JR and Hughes SP: Fibrous dysplasia of bone and the Weil-Albright syndrome. A study of thirteen cases with special reference to the orthopaedic treatment. Int Orthop 10: 53-62, 1986.

21. Leet AI, Boyce AM, Ibrahim KA, Wientroub S, Kushner H and Collins MT: Bone-grafting in polyostotic fibrous dysplasia. J Bone Joint Surg Am 98: 211-219, 2016.

22. Ippolito E, Bray EW, Corsi A, De Maio F, Exner UG, Robey PG, Grill F, Lala R, Massobrio M, Pinggera O, et al: Natural history and treatment of fibrous dysplasia of bone: A multicenter clinicopathologic study promoted by the European Pediatric Orthopaedic Society. J Pediatr Orthop B 12: 155-177, 2003.

23. Stanton RP: Surgery for fibrous dysplasia. J Bone Miner Res 21 (Suppl 2): P105-P109, 2006

24. Jung ST, Chung JY, Seo HY, Bae BH and Lim KY: Multiple osteotomies and intramedullary nailing with neck cross-pinning for shepherd's crook deformity in polyostotic fibrous dysplasia: 7 femurs with a minimum of 2 years follow-up. Acta Orthop 77: 469-473, 2006

25. Nishida Y, Tsukushi S, Hosono K, Nakashima H, Yamada Y, Urakawa $\mathrm{H}$ and Ishiguro N: Surgical treatment for fibrous dysplasia of femoral neck with mild but prolonged symptoms: A case series. J Orthop Surg Res 10: 63, 2015.

26. O'Sullivan $\mathrm{M}$ and Zacharin $\mathrm{M}$ : Intramedullary rodding and bisphosphonate treatment of polyostotic fibrous dysplasia associated with the McCune-Albright syndrome. J Pediatr Orthop 22: 255-260, 2002. 